\title{
Impact of Educational Practice According to the Context Unique to Japan through Introduction of International Baccalaureate
}

\author{
Yohei Moriguchi \\ Osaka University Human Science Department, Japan
}

\begin{abstract}
International Baccalaureate (called IB) has expanded its number in various parts of the world. This paper shows how IB programmes spanning the world change educational practices in the particular region and country, with a focus on Japan. There are a number of educational elements peculiar to Japan (the homeroom system, the comprehensive role of teachers, club activities, etc.) that present barriers to the introduction of Western-oriented IB programmes. At the same time, the government intends to improve its quality by incorporating IB into existing education curriculum in Japan. Though comparing Japan's public/private IB (and non IB) schools with International schools that offer IB programmes, this paper has significance in the aspect of investigating how the problems peculiar to that country are occurring in the practice of IB in Japan, nonWestern country, and of leading to an understanding of how changing educational practices can create merits and difficulties when attempting to merge national educational practices with overseas educational elements.
\end{abstract}

\section{Introduction}

International Baccalaureate (IB) is a non-profit educational institution founded in Geneva, Switzerland in 1968. The features of the program can be roughly divided into four elements:

(1) Centres on learners;

(2) Develops effective approaches to teaching and learning;

(3) Works within global contexts;

(4) Explores significant content. Working together

These four characteristics define an IB education [1]. It represents a unique educational philosophy focused on students. There are four IB programmes: the Primary Years Programme (PYP) for ages 3-12, the Middle Years Programme (MYP) for ages 11-16, the Diploma Programme (IBDP) for ages 16-19, and the Career- related Programme (IBCP) also for ages 16-19. In recent years, the "10 Learners Profile" that is based on all programs ("Inquires" "knowledgeable" "thinkers" "communicators" "principled" "open minded" "caring" "risk-takers" "balanced" and "reflective") and presented the guideline that the learner should aim for all target age groups. It is also close to the international mindedness and an important common basis connecting the above four programmes [2]. Through four programs for students aged 3 to 19 years, students acquire the intelligence, humanity, and social skills, necessary to learn and continue working to survive the rapidly changing global society [1]. Also, with conscious of the continuity of the curriculum of these three programs, International Baccalaureate Organisation designed the curriculums provide students with appropriate teaching according to the developmental stages of children. IB programmes actively encourage students studying in many parts of the world to understand/respect differences among people and recognize that ideas different from theirs can be equally valid. Ian Hill, deputy secretary general of International Baccalaureate, suggested that it is essential for international education to understand that people with different backgrounds have different opinions and insists on examining why they hold, and it leads to understanding and respecting other perspectives, leading to knowing where they came from [3]. In this way, IB programmes regard "international mindedness" as a central mission, attempting to define it in clearer terms and making efforts to cultivate in students a strong international awareness. All this requires critical thinking, collaboration skills, and respect for different cultures. For this reason, IB programmes seek to nurture young people with inquiring minds; they promote knowledge and compassion that will contribute to building a better, more peaceful world [3]. To achieve its goals, IB works with schools, governments and international organisations to develop a challenging international education programme and a strict evaluation system.

In addition, the International Baccalaureate Organisation is an advisory body of UNESCO and has a shared educational objective close to each 
other. Both UNESCO and International Baccalaureate have historically deeply involved. Briefly stating that, UNESCO also decided to support International Baccalaureate at the 18th General Assembly in 1974, and thereafter meetings will be held from time to time between UNESCO and IBO to seek concrete measures for financial support [4]. Also, in 1976, UNESCO decided to spend 260,000 US dollars, equivalent to $1 / 3$ of the original necessary expenses of international baccalaureate for two years [4].

The origin of the International Baccalaureate come from the idea of giving international schools an internationally accepted university entrance qualification at any university so that parents transferring between Europe, will not be adversely affected by college admission [5]. That is, IB was established from the needs of students going to international schools.

And, in order to complete secondary education at the international school where there are students with different nationalities, it was necessary to establish a common international curriculum independent of the education system of each country, at the time that international migration was becoming more active [6]. Also, from the reflection of the Second World War, it is said that the necessity of education based on the viewpoint of global pacifism that is not reflective of nationalism, that is not biased toward any country's educational policy was also required [7].

The initial concept and the current nature of IB have undergone significant changes. 640 schools of 721 schools (89\%) offering DP in the United States in 2011 were public schools, 139 schools of 217 IBDP schools (64\%) in the UK, 139 IBDP schools of 117 schools (84\%) in Canada, and 11 of the 62 IBDP schools (18\%) in Australia were public schools [8]. Thus, although previously provided to students attending international schools, public/private schools offer IB programme appeared.

IB world schools which only 47 schools existed in 1978 rapidly increased to 1,052 schools in 2000 and 3,035 schools in 2010 [5], 4,786 schools worldwide in 2018 [9]. International Baccalaureate has three branches in Africa Europe Middle East region, Asia Pacific region, Americas region, but the highest annual growth rate from 2015 to 2016 is the AsiaPacific region of three regions (the rate is $10.5 \%$ ) [10].

In addition, the numbers of higher education institutions that utilize the final test result of IBDP at the time of entrance examination have increased, and IBDP students send transcripts to over 3,300 higher education institutions across about 90 countries every year [10]. The background relates to the existence of statistical data on international Baccalaureate students in the screening of university entrance examination. International baccalaureate students have an advantage in going to a prestigious university.

For example, in the context of the United States, the passing rate to the IBDP students' Ivy League (generic name of eight prestigious private universities in the northeastern United States) is $313 \%$ higher than the whole [11]. The average point of SAT which is the unified entrance examination in the United States, of IBDP students is higher than the average of the American student as a whole in each subject [11]. In addition, because IB facilitate an access to universities abroad, IB has become well received by domestic students who are oriented to overseas, eager for learning in the multicultural environment, and improving their foreign language ability. However, it cannot be overlooked as a matter of concern about the concentration of IB schools. According to Bunnell [8], 58\% of IB schools are located in the "Big 4" countries (the United States, Canada, the UK, and Australia). Now, $60.9 \%$ of IB schools are located in the United States in 2017 [9]. Bunnell insists that IB is biased toward Western Europe because of the ubiquity of these areas.

\section{Status of the introduction of IB in Japan}

\subsection{Promotion to increase the number of $\mathrm{IB}$ schools by the Government in Japan}

In Japan, which is located in the Asia Pacific region, the number has also increased rapidly in recent years. The first IB school in Japan appeared in 1979 , yet there were no significant increases in the number of IB schools until recently. The turning point came in June 2012 with the announcement of the Global Human Resource Development Strategy under the Democratic administration [12]. The announcement called for 'up to 200 schools within five years that introduce IB programmes or conduct educational practice according to its guidelines'. Until March 2018, the Japanese government has taken measures to hold the IB teacher training workshop free of charge, which is a requirement to become an IB teacher. At the time of this recommendation, only 14 schools in Japan were certified by the International Baccalaureate Organisation, which provides the International Baccalaureate Diploma Programme. Most of these 14 schools were international or ethnic schools. However, by July 2017, there were 46 IB schools (22 offering PYP, 13 offering MYP, and 32 offering IBDP), and the number of public/private schools offering IB programmes has increased to 20 schools: five times the number in 2011. In addition, there are currently many more candidate schools in the process of becoming IB schools [13]. 
Nagayama, a chief of International Affairs in MEXT, explains three reasons why the government intends to introduce international baccalaureate from three perspectives [14].

Firstly, IB is beneficial for improving task discovery and resolution ability, communication skill and academic English language management ability, and to cultivate talented people globally. Indeed, as a curriculum tool to make the top $10 \%$ of students in Japan improve English skill and international mindedness of in Japanese schools, MEXT officially announced IBDP at the International Baccalaureate Forum [15]. The second point is expectation for enhancing the liquidity of human resources in directions from Japan to abroad and vice versa by introducing international standard education. Introducing IB enables Japanese high school students to enter foreign countries through setting up an educational environment responding to foreign country as well as foreign students coming to Japan. The third point is the hope of reforming the educational method of high school in Japan through the introduction of IB (The third will be described in detail later).

\subsection{Dual Language Programme}

International Baccalaureate Organisation has developed its expansion strategy. At the same time, searching for ways to adapt IB locally has changed the contents of education [16]. The interaction between local and global elements inevitably changes both local education and global education. One example is the establishment of "Dual Language Programme" that combine the official language (English, French, Spanish) and native language (here, Japanese), which can be seen as a unique way of introducing IB into the Japanese educational system. In May 2013, the International Baccalaureate Organisation and the Japanese Ministry of Education announced that they would begin a joint project on the development of IBDP programme in dual languages to promote the spread of IB programmes in Japan. At that time, the subjects covered under this project were Economics, History, Biology, Chemistry, Theory of Knowledge,

Extended Essay, and Creativity/Action/Service (called CAS). (Theory of knowledge, extended essay and CAS are core subjects of IBDP programme) [12]. Beginning in May 2014, students could also take IBDP classes and exams in Japanese for mathematics and physics. Students pursuing IBDP programme in bilingual languages are able to study two of six subjects in English and four in Japanese. In this way, the language barrier for introducing IB programme was reduced considerably by offering two-thirds of the full programme in Japanese [12]. And these movements are derived from the fact that focusing on aspects of improving critical thinking abilities and expressive skill, rather than improving the English language abilities of IB.

\subsection{Strong similarity between educational viewpoint aimed at by Japan and provided by IB}

Japanese non-IB schools are also interested in such skills that IB education fosters, and attempts are being made to incorporate them into the school classes, as mentioned previously. The skill capabilities promoted in IB programmes are very close to the capabilities that Japanese education seeks to develop in students, and it is expected that much of existing Japanese educational content will be transformed by the introduction of IB [17]. In fact, "The meeting of expert thinking about global human resources development centred on the international baccalaureate", which began in March 2007, referred to such an intention. In the "High School-University Connection Reform", which is being advanced by the Ministry of Education, changing from traditional knowledge-weighted academic examinations to a mechanism for comprehensively measuring knowledge skill, acquisition skill, thinking, judgment, expressive ability, and individuality and cooperativeness is being actively considered. In discussions of the next guidelines at the Ministry of Education for Curriculum, the topic of IB programmes is frequently taken up, and the content of the IB curriculum is generally regarded as an important reference. The curriculum of education in Japan has been gradually changing, but education as mere knowledge transmission and reliance on teachercentred classes persists. This runs counter to IB education, which focuses on student-centred classes and encourages students to improve their insight knowledge and critical thinking, and requires a test that can objectively measure such skills [12].

\subsection{Background of Japan's inability to smoothly introduce the IB programme}

The number of schools offering IB programmes in Japan has greatly increased in recent years. However, the current number is still far from the target of 200 schools. Despite the country's initiatives promoting IB programmes, these efforts have not gone far enough [4]. According to previous research, the cost of the process for obtaining IB school certification and the maintenance cost after certification are not small. The cost of IB teacher training is also quite high. These high costs are one of the reasons that IB introduction in Japan has fallen short. There are other reasons as well. There are criticisms that IB programmes are biased to the West, because the original birth of the IB is Western, etc. [18]. Looking 
at the history of IB, its origin was Geneva in Switzerland, and in the preparation of the test plan at the International Centre for Educational Research in 1969 , it was mostly made by experts from the West, as Alex Peterson's proposal is often reflected. He was the first Director General of IB and a staunch campaigner against what he regarded as the overspecialisation of British education at preuniversity level. His six-form reform plan in the UK led to IB curriculum structure. Criticisms that IB is Westerncentered still exist.

Drake [19] claimed that regions such as Asia, Africa and South America are culturally very different from the environment of the European region where IB were originally developed, it is not prudent to simply clone an educational system and methodology into each country.

Walker [18] examined the evidence from various authorities (philosophers, etc.) and analysed 10 Learner's Profile which is on the basis of the educational spirit of IB and considered how Learner's Profile are suitable for oriental culture in order to demonstrate that the educational culture of the West and the Orient is actually different. Walker also explains how the same words are translated differently by culture.

However, almost no studies analyzed through school surveys relating to the impact of the introduction and practice of IB in non-Western countries. Especially concerning nation-specific problems in introduction and practice in Japan located in the Orient, it has not been investigated deeply. Therefore, this study deals with this problem. Also, this study will investigate how the Japanese type of education (which is non-IB school) based on the educational theory of IB is being built.

\section{Research question and Methodology}

As a result of organising the previous research so far, the following two research questions emerged:

Q1. How Japan's educational practices are being transformed by the introduction of IB.

Q2. How the difficulties of introducing IB into the traditional Japanese system continue to be barriers to widespread acceptance.

Based on the above research question, this study will investigate how the transformation and difficulties peculiar to that country are occurring in the practice of IB in Japan, non-Western country. To examine these aspects, interviews and participant observations were conducted at international schools, private IB schools (A total of six schools, 15 teachers), and public/private non-IB schools (two schools) that offer some elements of IB (included participant observation over four months at international schools and private IB schools). The survey schools are listed in Table 1 at the end of the paper (Information about school name, school type, school location is also attached). At all IB survey schools, students are taught in English except for home language and foreign language subjects.

This study adopted a semi-structured interview. Kvale [20] defines the interview as obtaining a description of the life world of the interviewer on interpreting the meaning of the described phenomenon. Each interview conducted focuses on a series of themes, but do not stick to prepared questions, change the order to create a natural flow. In addition to the interview data of the teachers and the students, this study analyzed based on the documents issued by the survey schools, the materials obtained at the site of school, and the data through class observation.

\section{Results}

Firstly, all the surveyed public/private schools were designated Super Global High (SGH) Schools. Super Global High (SGH) Schools have the mission that contributes to the development of global leaders at high schools and other institutions, students acquire international interests, such as dealing with social issues, communication skills, and problemsolving skills, and fostering global leaders who can act internationally in the future. In 2016, only 123 schools are designated as SGH school by the government, and the number is not large compared with the whole. Schools that offer IB, or intend to introduce its philosophy, had already classes focus on English and problem-solving skills before the introduction.

\subsection{Transformation of Japanese educational practices accompanying the introduction of IB (Q1)}

It is apparent that Japan's educational practices are being transformed through the introduction of IB programmes. In the attempt to educate at Japanese non-IB surveyed schools using the idea of IB, it was found that class design mainly based on the subject Theory of knowledge. Theory of knowledge is one of the subjects of IBDP programme and examines the knowledge system of individual academic disciplines from an interdisciplinary point of view to cultivate critical thinking. Furthermore, this is a subject that recognizes the diversity of language, culture and tradition, deepens international understanding and corrects narrow-minded thinking. And, in this subject students learn how to acquire knowledge, learn how to use the knowledge gained, know the value, and explore differences in cross-cultural and time-based knowledge. In other words, we know 
"what we know, how we knew it, and how we can recognize and confirm knowing". Some schools putting IB elements into the existing subjects such as Japanese language class. In other schools there are some subjects similar to IB one, especially Theory of knowledge, in School Setting Subjects that teach classes by creating schools independently

In 2012, in "Survey research on the promotion of education based on the purpose of the International Baccalaureate", five schools were selected as research-designated schools for a period of three years. The study was intended to be a source of suggestions for incorporating elements of IB (in particular, the theory of knowledge) into non-IB schools [17]. School A and school B were chosen among the five schools. This study researched the two schools.

At School B, which is a non-IB school, students are practicing "Slow Reading" in their Japanese language class, while reading comprehension is emphasized in the current course of study guidelines [17]. The goal is for students to find the connection between the text of the teaching material and the knowledge acquired so far and to have students formulate their own questions and find appropriate answers.

In responding to an interview question regarding this effort, one teacher answered, "I realized a remarkable effect on the students' learning, which also led to an improvement in self-efficacy by connecting knowledge". Further efforts are underway at the school to raise awareness of IB elements such as ethics and society in other subjects. The result obtained at the present stage is that the average of the score (number of correct answers) of the "critical thinking ability test" has improved compared with the average point of six months ago.

It is desirable to ensure reliability, more detailed quantitative and qualitative survey, analysis.

School B (non-IB school) established General Department, specialized department "Human Inquiry Department" and "Nature Inquiry Department".Each of these specialized departments encourages students to acquire the ability to deepen the learning of humanities and attitude to explore human culture, society and behavior, and the skill to deepen learning of the mathematical system and attitude to explore natural phenomena. Also, at the same school, a class called "Inquiry Basis" is being conducted. This class was established in 1999 as a specialized subject, actively connecting "the Period of Integrated Study " and "Information", existing subjects in Japanese education. Through setting up an opportunity to think about Knowledge Question which a concept is emerging from the Theory of Knowledge in Inquiry Basis class. The school makes students cultivate the ability to capture inquiry activities from a multidimensional viewpoint.
Rubric is used for students' paper evaluation in the class of exploration foundation as well as evaluation of the class of IB. However, in order to conduct a more appropriate evaluation of the paper, consideration of Rubric's wording by more persons in charge is necessary. The same problem occurred at School A. Also, teachers (school A) said it is necessary to the construct the mechanism to evaluate teacher's evaluation whether it is valid or not, for example, sample several papers and evaluate it with all the teachers. And as future attempts, they suggested that it is also possible to promote students to take "Essential Questions", which is also the concept of Theory of Knowledge, into consideration in each subject. Questioning the essence of the subject framework to students and bringing together the knowledge learned in each subject, will bring closer to educational practices that make use of the idea of Theory of Knowledge more.

At the school where IB courses exist IB also affects the non-IB courses. School C (both IB courses and non-IB courses exist) introduced "Theory of Knowledge" into non-IB courses in the 10th grade, encouraging students to improve their critical thinking. "Inquiry Basis" is offered one hour each week in the 11th grade of non-IB courses. In other schools, efforts have been made to conduct activities more conscientiously using CAS evaluation methods and evaluation sheets for special activities such as cleaning. An interviewed student said that he was able to execute these activities considering things more deeply.

There are movements to be introduced by the Board of Education. For instance, Yamagata Prefectural Board of Education is conducting a prefecture-led initiative to establish an Inquiry course in six prefectural high schools in 2018. The course will focus on "Inquiry-based Learning" that tackles subjective and collaborative efforts toward solving self-discovered problems utilizing the basic knowledge and skills learned in each of the various subjects.

\subsection{The regional context in Japan and the difficulties arising from it $(\mathrm{Q} 2)$}

Next, in response to the criticism of whether IB programmes are offering a West-centred program, this study will describe matters arising when Japan located in the East introduces and practices IB; an interview about what kind of problem is arising as problems peculiar to Japan when introducing and practicing IB, to IB teachers and students.

According to Beverley's survey [15], IB students in Japan are required to attend classes (classical studies, citizenship, health, physical education, etc.) that do not have an equivalent in the international baccalaureate programme but are included in the Japanese high school curriculum to satisfy school 
qualification requirements. Even though there is research indicating that IB classes themselves require many tasks and the psychological stress level on students is high [21], the burden of taking additional classes is heavy. IB students in Japan who participate in club activities, which are held nearly every day after school, find it extremely difficult to complete their IB tasks. Traditionally, most students in Japan participate in club activities, but IB students face the dilemma of choosing between club activities and studying in their IB courses. Such a situation interferes with student learning and the practice of teaching. Focusing on the final exam, schools and students tend not to spend time on the DP core subjects (CAS, TOK, Extended Essay), as CAS is not covered on the exam, and Extended Essay and Theory of Knowledge count for only three points of 45 overall points in the IBDP programme.

In addition, many parents and students have common problems in progressing to the IB programme. Since the contents of IB education and the contents of the Japanese university examination are very different, both students and parents find it difficult to change direction from the IB programme to the conventional curriculum. In Japan, unlike the United States, the option of taking part of the IB programme and making it part of the certificate for attending university does not exist at present, and once students enter the IB programme, they must earn the full diploma to enter university. The interview teacher (school C, D) said that the subject of IB itself is quite different from the traditional Japanese teaching. Especially Japanese teachers said that Japanese students tend to have low consciousness of connection between subjects and low awareness of academic honesty (Academic honesty means the intellectual property rights and whether the students themselves really worked), the traditional Japanese lessons tend not to deal with things that are similar to them. IB is curriculum designed to make students conscious of academic honesty and connection between subjects throughout the subjects and deals more concretely on the connection between subjects in Theory of

Knowledge class. In IB programme where classes are conducted only in English, except for the Japanese language, foreign language class, students who do not have strong English ability are often advised not to take IB courses so as not to have to drop them when they become overly difficult.

The interview teachers (School C, D) said. Most of public/ private school IB schools only introduce DP. Therefore, there are students suffering from divergence between contents learned to junior high school and contents of DP starting from high school.

Other elements peculiar to Japan are also cause for difficulty when introducing IB. In Japan, the homeroom system exists in most, if not all, schools. Under this system, teachers take charge of virtually all tasks, from office work to counselling their students (As evidence backed by concrete statistics, the proportion of professional staffs except teachers: $18 \%$ Japan, 44\% USA, and 49\% UK). The many foreign teachers participating in IB programmes are quite likely to be unfamiliar or uncomfortable with this part of the educational culture.

In addition, most parents do not have a high level of English proficiency, which means detailed communication with foreign IB teachers must be supported by a Japanese IB teacher, making the burden on the Japanese IB teacher quite large.

If foreign teachers must face the challenge of working in an unfamiliar environment, the reverse is also true. In promoting IB programmes, Osako asserts that Japanese teachers involved in IB must internalize the spirit of IB programmes born in the West [22]. This means that Japanese IB teachers need to transform their own teaching methods. They cannot merely borrow ideas on a superficial level but must truly understand and embrace the essence of IB. In the past few years, there have been multiple teacher transfers in which teachers who taught in the standard Japanese curriculum suddenly found themselves teaching IB classes in the next fiscal year. As previously mentioned, the content of education greatly differs between the traditional Japanese system and IB. In interviews conducted for this study, many Japanese IB teachers say that they are not used to teaching classes in which they serve as facilitators to draw out ideas from their students. They report not knowing how to handle evaluation criteria for descriptive answers or how to cultivate the descriptive skills of their students.

There are other aspects of the IB programmes that are unfamiliar to Japanese teachers. These include elements such as academic honesty and working with full-time counsellors who are assigned to various parts of the programmes. One interviewed teacher commented, 'While there are experts such as a TOK and CAS coordinators, and a counsellor for guidance on overseas universities, Japanese teachers, who are used to doing everything from office work to course guidance, frequently oppose the process of introducing these specialists'.

According to the interview teachers (School C, D), both IB courses and non-IB courses exist in each public/ private IB school in Japan, and the IB course is only a part of the whole school. There is a fact that it must be carried out with the help of a career guidance counselor for IB students to advance to university abroad. However, for Japanese schools whose Japanese examination is determined almost by the points in the center examination, it is not possible for schools to gain an understanding of the necessity of borrowing the power of course counselors easily. Therefore, Due to the influence of Japanese traditional view on education, there is also a problem that there is a difference in consciousness about the 
necessity of the counselor's guidance between the IB and the non-IB course.

At international schools that have adopted IB programmes, the above challenges do not appear to be quite so difficult (School C, D, E, F, and other schools). In order not to be influenced by the Japanese system, elements of the Japanese educational culture such as the homeroom system and high-loading department activities are not typically present. Thus, the problems described above can be regarded as problems peculiar to public / private IB schools

\section{Conclusion and Future Prospects}

As seen from the above, IB programmes are having an influence on Japanese education. However, they also face quite a few barriers, including differences in the role of the teacher in IB courses, excessive club activities and a homeroom system that is unique to Japanese schools. One way to overcome such barriers is to prepare for a stronger mutual understanding between Japanese teachers and overseas teachers and to develop cooperating mechanisms. In this regard, the role of the IB coordinator and his/her ability to assemble a proper group of teachers are very important (particularly with respect to the teacher interviews). It is also necessary to have teachers and administrators internalize the spirit of IB. To accomplish this will require intensive training.

In response to this situation, courses have been newly established to acquire IB Educator Certificate rapidly in Japan (Tsuru Culture University, University of Tsukuba, Okayama University of Science, Hiroshima University). There is a movement in Japan that candidates of IB teachers understand international Baccalaureate educational philosophy through education at the university. In order to be an IB teacher, it is possible to satisfy the requirement only by participating in the IB teacher training workshop three times, but courses at the university have a role to enrich the IB teacher training and understanding IB educational philosophy will accelerate. However, these courses have only just begun, future work have to figure out what kind of education based on the situation in Japan is provided in the courses. While the number of IB is increasing in the world including Japan, not simply cloning and incorporating the IB program, but promoting introduction of IB with harmonizing the elements of IB and the nature of the education of the nation is important. The focus of this study is on IB programmes in public/private schools. Future work will seek to clarify how educational practice differs between dual language IB programmes and conventional IB programmes.

IB, originally targeted children who learn abroad, has become being offered to children born and raised in Japan with Japanese nationality. Particularly in schools that introduce Dual Language Programme, this is remarkable. It is a mono-culture environment that a large proportion of Japanese students are composed, and it is necessary to conduct ongoing investigation as to how IB education is provided. It is assumed that differences in educational practices related to the cultivation of international mindedness, which is the mission of IB programmes, will appear.

A study by Hayden, Thompson [23] reported that the most important factor in developing an international perspective is that it is being exposed to different cultures both inside and outside the school. At IB class, many opportunities for exchange and discussion outside the classes are made and it is considered that the existence of students and people from different countries inside and outside the school play an important role in their school life. In fact, interview teachers from international schools and private schools (School C, D, E, F) answered that classes with people from many different countries are more effective for nurturing an international mindedness. As a future task, by comparing the degree of cultivation of the international mindedness in international schools with multicultural environments and private / public schools in a minocultural environment, a quantitative and qualitative survey on the effectiveness of the curriculum is desired.

Table 1. List of survey school

\begin{tabular}{|c|c|c|c|}
\hline School name & School type & $\begin{array}{c}\text { School } \\
\text { location }\end{array}$ & $\begin{array}{c}\text { Offering the } \\
\text { kinds of IB } \\
\text { programme }\end{array}$ \\
\hline & & & \\
\hline School A & non-IB, Public school & Japan & - \\
\hline & & & \\
\hline School B & non-IB, Public school & Japan & \\
\hline & & & \\
\hline School C & IB, Private school & Japan & IBDP \\
\hline & & & \\
\hline School D & IB, Private school & Japan & IBDP \\
\hline & & & \\
\hline School E & IB, International school & France & PYP, MYP, DP \\
\hline & & & \\
\hline School F & IB, International school & U.K. & PYP, MYP, DP \\
\hline
\end{tabular}

\section{References}

[1] International baccalaureate Organisatiion "What is an IB education?", www.IBO.org, 2013. Retrieved from: http://www.ibo.org/globalassets/digitaltookit/brochures/wh at-is-an-ib-education-en.pdf (Accessed: 18 July, 2017)

[2] International baccalaureate Organisatiion, "IB learner profile booklet", ibo. org, 2006. Retrieved from: http://www.midpac.edu/downloads/iblearnerprofile.pdf (Accessed: 18 February, 2018) 
[3] International baccalaureate Organisatiion "Towards a continuum of international education", www.IBO.org., 2008, (Accessed: 18 July, 2017)

[4] Fukuda, K., (2015). Kokusai bakarorea to korekara no nyushi kaikaku - chi wo souzou suru akutelibura-ning, Aki shobou, Japan.

[5] Hanai, K., (2006). "Igirisu ni okeru kokusai bakarorea ninshou ni tomonau shikakushiken seido henyou ni kansuru kenkyu", Hikaku kyoikugaku kenkyu, Vol.52, pp. 90-112.

[6] Hill, I. 2002 "The International Baccalaureate Policy process in education', Journal of Research in International Education, pp. 183-211.

[7] Tarc, P. "What is the International in the International Baccalaureate?" Journal of Research in International Education, 2009 , pp. 235-261

[8] Bunnell, T., (2008). "The global growth of the International Baccalaureate Diploma Programme over the first 40 years: A critical assessment", Comparative Education, pp.409424.

[9] IBO, "official website", Retrieved from: http://www.ibo.org/ (Accessed: 18 February, 2018)

[10] IBO, "The IB Diploma Programme statistical bulletin", www.IBO.org., 2016

[11] Country report: United States of America. "The IB diploma graduate destinations survey"', i-graduate.org., 2012

[12] MEXT, "Kokusai bakarorea ni kannsuru teigen nado", (2017). Retrieved from: http://www.mext.go.jp/a_menu/ kokusai/ib/1352964.htm. (Accessed: 18 July, 2017)

[13] International baccalaureate organization, "The IB by country", ibo.org, 2017, Retrieved from: http://www.ibo. org/about-the-ib/the-ib-by-country (Accessed 18 July, 2017).

[14] Nagayama, K., (2013). "Guro-baru jinzai ikusei to kokusai bakarorea ni tsuite" Kagaku to kyoiku, pp. 330333.

[15] Yamamoto, B.A., (2016). "Implementation and Impact of the Dual Language IB DP Programme in Japanese Secondary School final report", ibo.org, Japan.

[16] Hill, I., (2006). "Do International Baccalaureate programs internationalise or globalise?" International Education Journal, pp. 98-108.

[17] MEXT, "Kokusai bakarorea no shushi wo fumaeta kyoiku no suishin", Japan, 2017 Retrieved from: http://www.mext.go.jp/a_menu/shotou/kyoiku_kenkyu/ind ex.htm?utm_medium=twitter. (Accessed 18 July, 2017).

[18] Walker, G., (2010), "East is East and West is West", ibo.org.
[19] Drake, B., (2004). "International Education and IB Programmes Worldwide Expansion and Potential Cultural Dissonance" Journal of research in international education, pp. $189-205$

[20] Kvale, J., (2007). Doing Interviews, SAGE Publications.

[21] Iwasaki, K., Osako, H, Kokusai, (2017). Bakarorea no genzai, Jiazu kyoiku shinsha, Japan, 2017.

[22] Shaunessy, E., Suldo, S.M., Hardesty, R.B., Shaffer, E.J., (2006). School Functioning and Psychological WellBeing of International Baccalaureate and General Education Students A Preliminary Examination. pp. 76-89.

[23] Hayden, M., Rancic, B. and Thompson, J. J., (2000). "Being International: student and teacher perceptions from international schools", Oxford Review of Education, pp. 107-123. 